\title{
Residual Perception of Biological Motion in Cortical Blindness
}

Ruffieux Nicolas*a, Ramon Meike ${ }^{* a}$, Lao Junpeng ${ }^{* a}$, Colombo Françoise ${ }^{\mathrm{b}}$, Stacchi Lisa ${ }^{\mathrm{a}}$, Borruat

François-Xavier $^{\mathrm{c}}$, Accolla Ettore ${ }^{\mathrm{b}-\mathrm{d}}$, Annoni Jean-Marie ${ }^{\mathrm{b}-\mathrm{d}} \&$ Caldara Roberto $^{\mathrm{a}}$ 
1

2

3

4

5

\section{Abstract}

From birth, the human visual system shows a remarkable sensitivity for perceiving biological motion. This visual ability relies on a distributed network of brain regions and can be preserved even after damage of high-level ventral visual areas. However, it remains unknown whether this critical biological skill can withstand the loss of vision following bilateral striate damage. To address this question, we tested the categorization of human and animal biological motion in $\mathrm{BC}$, a rare case of cortical blindness after anoxia-induced bilateral striate damage. The severity of his impairment, encompassing various aspects of vision (i.e., color, shape, face, and object recognition) and causing blind-like behavior, contrasts with a residual ability to process motion. We presented $\mathrm{BC}$ with static or dynamic point-light displays (PLDs) of human or animal walkers. These stimuli were presented either individually, or in pairs in two alternative forced choice (2AFC) tasks. When confronted with individual PLDs, the patient was unable to categorize the stimuli, irrespective of whether they were static or dynamic. In the $2 \mathrm{AFC}$ task, $\mathrm{BC}$ exhibited appropriate eye movements towards diagnostic information, but performed at chance level with static PLDs, in stark contrast to his ability to efficiently categorize dynamic biological agents. This striking ability to categorize biological motion provided top-down information is important for at least two reasons. Firstly, it emphasizes the importance of assessing patients' (visual) abilities across a range of task constraints, which can reveal potential residual abilities that may in turn represent a key feature for patient rehabilitation. Finally, our findings reinforce the view that the neural network processing biological motion can efficiently operate despite severely impaired low-level vision, positing our natural predisposition for processing dynamicity in biological agents as a robust feature of human vision.

Key words: Cortical blindness, biological motion, residual visual ability, striate damage, task dependency, eye tracking 


\section{Introduction}

Cortical blindness is a rare syndrome defined as severe loss of vision resulting from damage to the primary visual cortex (Aldrich et al., 1987; Flanagan et al., 2009). Compared to bilateral lesions, consequences of striate damage are reported much more commonly in cases of unilateral lesions. Such studies have reported preserved cognitive abilities in the absence of awareness, i.e. blindsight, in patients' blind visual fields using different types of stimuli (Sanders et al., 1974; Weiskrantz et al., 1974; for a review see Weiskrantz, 2009). For instance, the patient JS exhibited normal electrophysiological responses on the P3 component to prespecified target words presented in her blind hemifield (e.g., Shefrin et al., 1988), while GY was able to distinguish facial expression of emotions (de Gelder et al., 1999).

Detailed investigations of residual abilities in patients' blind fields have often involved motion conveying stimuli. These studies indicate that, generally, patients' awareness fluctuates and depends on nature of stimuli, paradigms, and tasks used (e.g., Hervais-Adelman et al., 2015; Weiskrantz et al., 1995; Zeki and Ffytche, 1998). For instance, GY exhibited different levels of awareness for nonidentifiable visual input (Barbur et al., 1993; Weiskrantz et al., 1995). More precisely, although his discrimination performance correlated with reported awareness (Zeki and Ffytche, 1998), he was nonetheless "able to discriminate correctly while being unaware" (p.32). Finally, neuroimaging studies involving presentation of motion conveying stimuli to patients with unilateral striate damage have demonstrated extrastriate activation in absence of striate input (Ajina et al., 2015a, 2015c; Barleben et al., 2015; Goebel et al., 2001; Zeki and Ffytche, 1998).

Detailed reports of patients with cortical blindness due to bilateral striate damage are far fewer in number compared to unilateral cases. Individual case reports include patients whose lesions occurred at birth or young age (Bova et al., 2008; Giaschi et al., 2003), as well as those acquired in adulthood (case TN, reported in Pegna et al., 2005; Burra et al., 2013; de Gelder et al., 2008; HervaisAdelman et al., 2015; case SBR, reported in Bridge et al., 2010; see also Riddoch, 1917). Importantly, 
while the prior have been reported to show reasonable improvements of visual functions, this does not appear to be the case for patients whose lesions occurred in adulthood (see also Zihl, 2000).

Despite the extreme severity of the visual deficits causing blind-like behavior in patients with bilateral damage, these patients commonly present with residual, rudimentary visual abilities. Reviewing 25 cases of cortical blindness, Aldrich et al. (1987) reported chronic complete cortical blindness in less than $10 \%$ of the patients (for an even lower prevalence, see Zihl, 2000), while residual light or motion perception was commonly found. The presence of residual visual abilities subsequent to bilateral striatal damage in humans coincides with findings from animal studies. For instance, Denny-Brown and Chambers (1955) reported that monkeys who had undergone bilateral V1ablation were able to localize moving objects, while others reported residual visuo-motor ability in rodents (Carey et al., 1990). Similarly, both TN and SBR have independently been reported as possessing residual motion perception abilities. Both patients showed above chance performance for detection of dynamic stimuli, although SBR's performance varied across visual fields (Bridge et al., 2010; Hervais-Adelman et al., 2015). In both cases, dynamic stimuli elicited activation in cortical regions associated with motion processing. Together, these results are in line with the idea that residual abilities observed in cortical blindness, in particular relating to motion perception, are mediated by alternative pathways, i.e. those bypassing striate cortex (Bridge et al., 2010; HervaisAdelman et al., 2015).

However, to the best of our knowledge, the processing of biological motion (BM) has never been tested in a case of cortical blindness due to bilateral striate damage. This is interesting, as across species, processing of BM is one of the most robust abilities of the visual system (Neri et al., 1998). Individuals who suffered complete blindness due to dense bilateral congenital cataracts show severe visual impairments years after surgical correction, including that of global motion processing, but intact BM processing (Bottari et al., 2015; Hadad et al., 2012). Vallortigara and colleagues (Vallortigara et al., 2005; see also Vallortigara and Regolin, 2006) reported that newly hatched chicks reared in complete darkness showed a preference for BM of their own, as well as other species. In humans, developmental studies have reported BM processing in neonates as early as 10h post-partum 
(Bardi et al., 2014; Simion et al., 2008) suggesting that detection and interpretation of BM is most probably hardwired. However, whether processing of $\mathrm{BM}$ - a critical biological ability essential for survival - is spared in cortical blindness remains an open question.

To this aim, the present study aimed at determining whether BM can be accurately processed in cortical blindness. We tested BC, a patient who suffered from severe hypoxia that caused bilateral lesions in the striate cortex. Similar to the patient TN (see above), BC presents with chronic cortical blindness, i.e. he is unable to visually describe or identify static or moving stimuli by sight. However, mirroring reports of residual visual processing in cortical blindness, he can show awareness for moving items, and even catch items thrown at him (see Supplementary Video 1 for a demonstration of BC's ability to process motion). BC's main complaint concerns his inability to identify people based on their visual appearance. In particular, he regrets not being able to identify his wife, although according to his anecdotal self-report, he sometimes succeeds to identify her based on her gait.

To clarify BC's ability in processing BM we used human and animal point-light displays (PLDs) which highlight body joints and trigger the impression of animate motion (see e.g., Hadad et al., 2015; Johansson, 1973; Troje, 2012). The PLDs of biological agents were presented under varying conditions (upright, inverted, scrambled, static, dynamic), as well as under different task constraints (identification of an individual PLD vs. selection of a prespecified PLD among a pair of stimuli). To anticipate our findings, BC was unable to identify individually presented PLDs. However, in notable contrast, when presented with two dynamic PLDs simultaneously, he could discriminate with high fidelity between human and animal walkers. Moreover, he displayed normal gaze patterns in this 2AFC task. Our findings add novel insights into the limited investigations of cortical blindness. Importantly they highlight, for the first time to our knowledge, the remarkably robust residual capacity in cortical blindness to perceive motion that is conveyed by living biological agents. 


\section{Methods}

\subsection{Patient BC}

BC (male, right-handed; born 1954, 62 years of age at the time of testing) suffered from severe anoxic encephalopathy caused by a heart attack in March 2010. Neuro-ophthalmological assessment was performed 20 months after the heart attack. Visual acuity was limited to the perception of hand movements only in both eyes. Color vision was absent as the patient failed to identify the color of large brightly colored objects. Kinetic manual perimetry (Goldmann) revealed a marked to severe concentric loss of sensitivity in both eyes with a partial left homonymous hemianopsia (Figure 1). Oculomotility, motion detection, ocular and fundus examinations were normal in both eyes. Visual evoked potentials (Nicolet 1015 visual pattern shift monocular stimulation at a rate of $1.9 \mathrm{~Hz}$ ) showed a P1 latencies of 106 and $104 \mathrm{~ms}, \mathrm{~N}$ to $\mathrm{P}$ amplitudes were 3.77 and $3.85 \mu \mathrm{V}$ for the right and left eye, respectively.

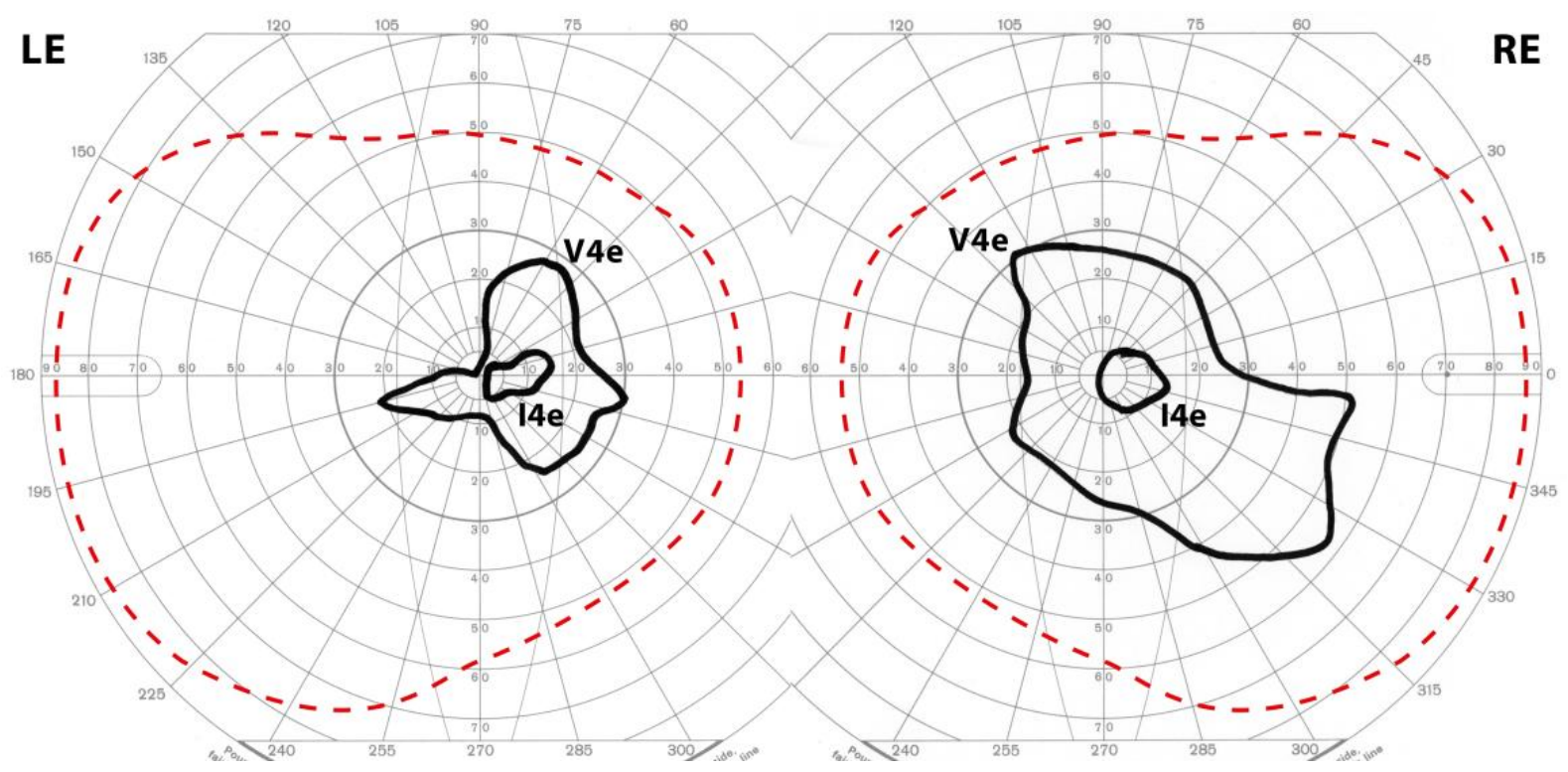

Figure 1. Results of kinetic manual perimetry (Goldmann). Marked to severe loss of sensitivity (isopter obtained with the largest stimulus V4e) and a subtotal left homonymous hemianopsia (isopter obtained with the smaller stimulus I4e) were present in both eyes. The dotted red line depicts the normal limits of the isopter obtained with the V4e stimulus in an agematched normal subject. $\mathrm{LE}=$ left eye; $\mathrm{RE}=$ right eye; $\mathrm{V} 4 \mathrm{e}=64 \mathrm{~mm} 2$ round stimulus of 1000 apostilbs luminance; I4e = $1 / 4 \mathrm{~mm} 2$ round stimulus of 1000 apostilbs luminance.

Neuroradiological assessment of BC's structural MRI (performed four months after the heart attack - Figure 2) revealed moderate cortical-subcortical atrophy and posterior white matter hyperintensity affecting bilateral striate areas. Due to the delay between anoxia and MRI, no gyriform signal 

in T2 and Flair sequences strongly suggest delayed-onset white matter anoxic lesions (Sawada et al.,

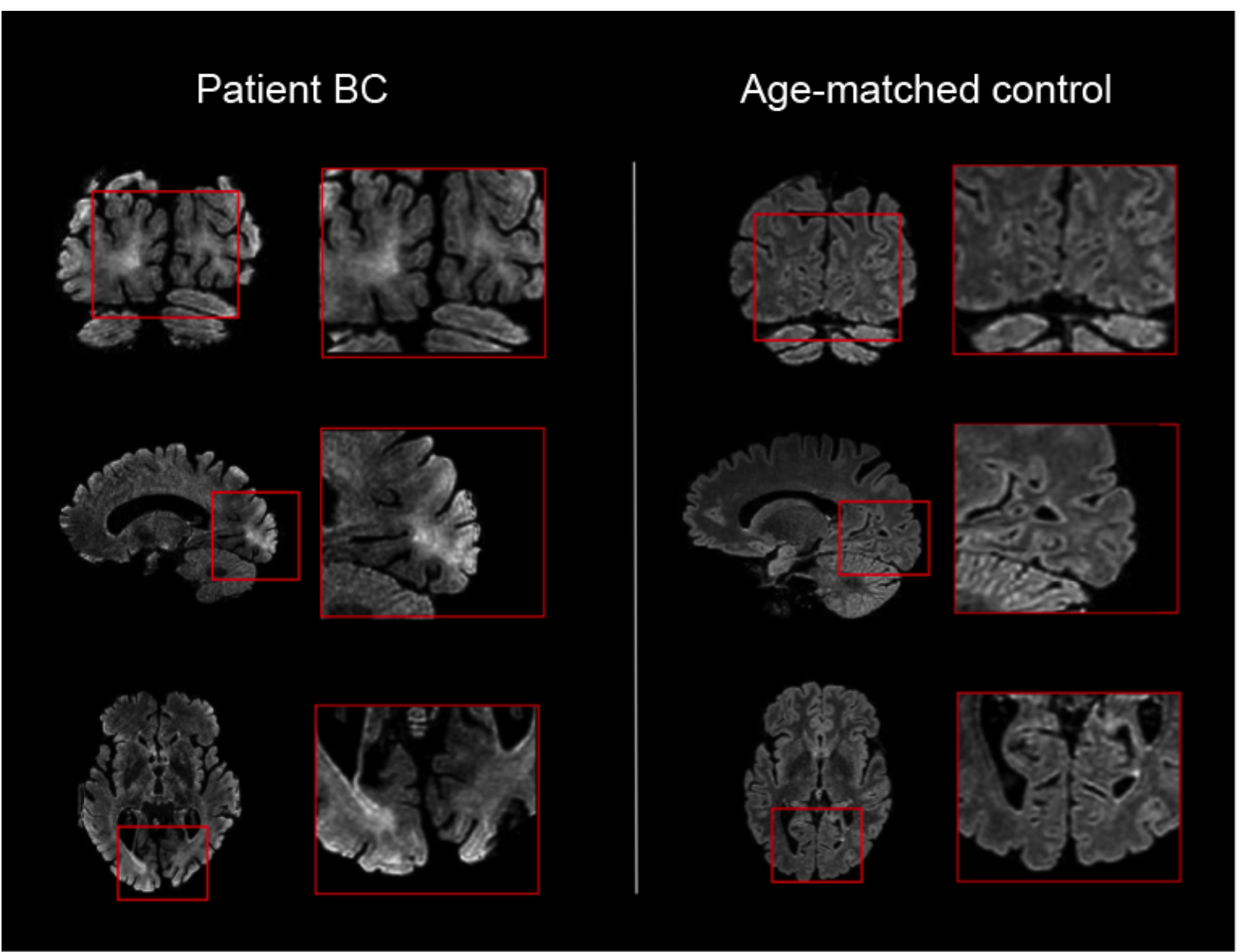

Figure 2. BC's structural MRI acquired four months after anoxic encephalopathy. The patient's FLAIR MRI (left) is compared to an acquisition from a healthy, age-matched subject (right). For illustration purposes, volumes have been biascorrected, skull stripped, and underwent arithmetic squaring. The patient's occipital white matter lesions are rather diffuse and include projections to early visual areas including V1, V2, and possibly V3; the medial temporal sulcus and neighboring areas are relatively spared.

Neuropsychological assessment (see Table 1) performed four months after the heart attack

showed a severe diffuse cognitive impairment. BC's main cognitive symptoms included cortical

blindness with Anton-Babinski syndrome (anosognosia of visual deficit), dysexecutive syndrome,

amnesic syndrome (both retro- and anterograde difficulties), ideo-motor apraxia, as well as spatial and

\footnotetext{
${ }^{1}$ Although hypoxia is often associated with hippocampal hypoxia and watershed cerebral cortex alteration (Caine and Watson, 2000), cortical blindness with relative preservation of visual evoked potentials has also been described in such patients (Tsutsui et al., 1984). The MRI changes due to cortical striate abnormalities in such diseases are generally post-acute (in the first month) and sometimes difficult to visualize while delayed leukoencephalopathy and atrophy has been repeatedly described (Chen-Plotkin et al., 2008; Margolin et al., 2007).
} 
temporal disorientation. During the first month, BC also presented with visual and auditive hallucinations, confabulations, along with episodes of agitation and aggressiveness, which rapidly regressed after behavioral multidisciplinary approach and pharmacological treatment (Trazodone and Quetiapine). Contrariwise, linguistic abilities were largely intact, with fluent and informative spontaneous speech, and preserved oral comprehension. Assessment of verbal intelligence (WAIS-III) yielded a Verbal IQ score of 74. BC's most pronounced deficits were observed in the visual domain. Unable to identify objects visually, he could readily do so provided their verbal definition, or based on haptic exploration. Visual discrimination or matching of shapes, line drawings of objects, real objects, letters, faces, or colors was impossible. Copying letters and simple geometrical shapes was also severely impaired. There were no clinical signs of visual neglect, and the eye movement recordings described in detail below (see 2.4 and 2.5) demonstrate that BC spontaneously fixates both the left and right visual fields, as do healthy young and age-matched controls (Figure 4). Overall, BC behaved as though he were blind, except for the lack of usage of strategies to compensate for his visual impairments. BC was discharged and returned home eight months after the heart attack. Regular follow-up neuropsychological assessments showed mild overall improvements, particularly in the memory domain. BC showed the typical evolution of cortical blindness (Bender and Furlow, 1945). Notwithstanding mild improvements in perceiving light, motion, contrast and colors, his cortical blindness remains severe: he is unable to navigate independently, and relies entirely on his wife and caregivers for activities of daily living. A brief neuropsychological reexamination of BC's visual abilities performed in 2016 showed no significant improvement compared to the assessment in 2010, but mild improvements in executive functions were observed (see Table 1). Partial anosognosia of his visual deficits persists, although he acknowledges his visual deficits when strongly confronted with them; language comprehension and expression remain largely preserved.

In contrast to his severe visual deficits, $\mathrm{BC}$ presents with a striking ability to perceive motion. For example, the patient was readily able to catch a ball thrown at him, even though he could not visually identify the object (see Supplementary Video 1). He is highly cooperative and willing to participate in experiments, but fatigues quickly, making extensive psychophysical testing (see e.g., 
1 Bridge et al., 2010) impossible. In summary, neuropsychological assessments and the patient's self-

2 reports indicate that $\mathrm{BC}$ i) presents with chronic cortical blindness; ii) has some residual visual 3 abilities, in particular in perceiving motion; iii) is not aided by motion when identification of non-

4 biological stimuli is concerned, although it might improve his ability to process biological stimuli.

5 Table 1. Results of BC's neuropsychological assessment four months after brain damage.

\begin{tabular}{|c|c|c|}
\hline Test & Performance & $\begin{array}{l}\text { Qualitative } \\
\text { descriptor }\end{array}$ \\
\hline \multicolumn{3}{|l|}{ Orientation } \\
\hline Temporal & $0 / 5$ & $\mathrm{D}$ \\
\hline Spatial & $0 / 3$ & $\mathrm{D}$ \\
\hline \multicolumn{3}{|l|}{ Language } \\
\hline $\begin{array}{l}\text { Oral expression } \\
\text { Spontaneous } \\
\text { Vocabulary subtests (WAIS-III) } \\
\text { Verbal Fluency (1') } \\
\text { Litteral (M) } \\
\text { Semantic (animals) } \\
\text { Naming objects on verbal definitions } \\
\text { Sentence completion } \\
\text { Repetition (complexes sentences, logatomes) }\end{array}$ & $\begin{array}{l}\text { Fluent and informative, mild word } \\
\text { finding difficulties } \\
\text { SS }=8 \\
9 \\
7 \\
9 / 10 \\
12 / 13 \\
\text { Preserved }\end{array}$ & $\begin{array}{l}\text { Lim } \\
\text { N } \\
\text { D } \\
\text { D } \\
\text { N } \\
\text { N } \\
\text { N }\end{array}$ \\
\hline $\begin{array}{l}\text { Oral Comprehension } \\
\text { Situational } \\
\text { Onomatopoeia recognition } \\
\text { Apragmatic/passive sentences } \\
\text { Syllables discrimination } \\
\text { Verbal Associative Color test } \\
\text { Comprehension subtest (WAIS-III) } \\
\text { Verbal Comprehension Index }\end{array}$ & $\begin{array}{l}\text { Preserved } \\
\text { Preserved } \\
\text { Mild difficulties } \\
34 / 40 \\
8 / 10 \\
\text { SS }=9 \\
79\end{array}$ & $\begin{array}{c}\mathrm{N} \\
\mathrm{N} \\
\mathrm{D} \\
\mathrm{Lim} \\
\mathrm{Lim} \\
\mathrm{N} \\
\mathrm{Lim}\end{array}$ \\
\hline $\begin{array}{l}\text { Written expression } \\
\text { Simple words } \\
\text { Sentences } \\
\text { Spelling }\end{array}$ & $\begin{array}{l}\text { Handwriting severely impaired } \\
2 / 2 \\
\text { Impossible } \\
2 / 5\end{array}$ & $\begin{array}{l}\mathrm{D} \\
\mathrm{N} \\
\mathrm{D} \\
\mathrm{D}\end{array}$ \\
\hline Reading & Impossible & $\mathrm{D}$ \\
\hline \multicolumn{3}{|l|}{ Oral calculation } \\
\hline $\begin{array}{l}\text { Simple arithmetic facts } \\
\text { Simple Calculation } \\
\text { Arithmetic subtest (WAIS-III) } \\
\text { Number semantic } \\
\text { Quantity estimation } \\
\text { Number oral comparisons }\end{array}$ & $\begin{array}{l}\text { Failed } \\
\text { Failed } \\
\mathrm{SS}=2 \\
3 / 9 \\
\text { Preserved } \\
\text { Preserved }\end{array}$ & $\begin{array}{l}\mathrm{D} \\
\mathrm{D} \\
\mathrm{D} \\
\mathrm{D} \\
\mathrm{N} \\
\mathrm{N}\end{array}$ \\
\hline \multicolumn{3}{|l|}{ Praxia } \\
\hline $\begin{array}{l}\text { Ideomotor } \\
\text { Ideational } \\
\text { Constructional } \\
\text { Buccofacial }\end{array}$ & $\begin{array}{l}\text { Failed } \\
\text { Failed } \\
\text { Failed } \\
\text { Preserved }\end{array}$ & $\begin{array}{l}\mathrm{D} \\
\mathrm{D} \\
\mathrm{D} \\
\mathrm{N}\end{array}$ \\
\hline
\end{tabular}




\begin{tabular}{|c|c|c|}
\hline Visual processing & & \\
\hline $\begin{array}{l}\text { Visual discrimination and matching of real objects, } \\
\text { colors, faces } \\
\text { VOSP Shape Detection screening subtest } \\
\text { Color matching } \\
\text { Associative Color test } \\
\text { Familiar and Famous Faces recognition } \\
\text { Mental imagery production } \\
\text { Identification of body parts }\end{array}$ & $\begin{array}{l}\text { Failed* } \\
9 / 20^{\mathrm{a}} \\
0 / 10^{*} \\
0 / 10^{*} \\
0 / 10^{*} \\
\text { Failed* } \\
4 / 10^{\mathrm{b}}\end{array}$ & $\begin{array}{l}D \\
D \\
D \\
D \\
D \\
D \\
D\end{array}$ \\
\hline \multicolumn{3}{|l|}{ Auditory processing } \\
\hline $\begin{array}{l}\text { Familiar noises recognition } \\
\text { Pitch and tone recognition } \\
\text { Intensity differences perception }\end{array}$ & $\begin{array}{l}6 / 10 \\
\text { Preserved } \\
8 / 10\end{array}$ & $\begin{array}{c}\text { Lim } \\
\mathrm{N} \\
\mathrm{Lim}\end{array}$ \\
\hline \multicolumn{3}{|l|}{ Memory } \\
\hline $\begin{array}{l}\text { Immediate } \\
\quad \text { Auditivo-verbal span }\end{array}$ & 5 & Lim \\
\hline $\begin{array}{l}\text { Anterograde verbal } \\
\text { Assessor's name recall } \\
10 \text { words list (Rey) }\end{array}$ & $\begin{array}{l}\text { Preserved } \\
\text { Immediate recalls (Trials } 1-3 \text { ): } 1 / 2 / 2 \\
\text { Delayed recall: } 0 / 10 \\
\text { Recognition: } 2 / 10 \text { ( } 8 \text { false alarms) }\end{array}$ & $\begin{array}{l}N \\
D \\
D \\
D\end{array}$ \\
\hline $\begin{array}{l}\text { Retrograde } \\
\text { Objects structural properties } \\
\text { Autobiographical } \\
\text { Episodic collective } \\
\text { Information subtest (WAIS-III) } \\
\text { Similitudes subtest (WAIS-III) } \\
\text { Encyclopedic knowledge } \\
\text { Celebrities knowledge } \\
\text { Drawing on demand }\end{array}$ & $\begin{array}{l}5 / 8 \\
4 / 10 \\
3 / 10 \\
\mathrm{SS}=3 \\
\mathrm{SS}=7 \\
7 / 8 \\
39 / 40 \\
\text { Impossible }\end{array}$ & $\begin{array}{l}D \\
D \\
D \\
D \\
N \\
N \\
N \\
D\end{array}$ \\
\hline \multicolumn{3}{|l|}{ Executive functions } \\
\hline Frontal Assessment Battery & $10 / 15^{\mathrm{c}}$ & $\mathrm{D}$ \\
\hline $\begin{array}{l}\text { Working memory subtest (WAIS-III) } \\
\text { Archaic reflexes }\end{array}$ & $\begin{array}{l}50 \\
\text { No grasping/palm-chin reflex }\end{array}$ & $\begin{array}{l}\mathrm{D} \\
\mathrm{N}\end{array}$ \\
\hline \multicolumn{3}{|l|}{ Global Scale } \\
\hline $\begin{array}{l}\text { Verbal IQ (WAIS-III) } \\
\text { Verbal Comprehension index (WAIS-III) }\end{array}$ & $\begin{array}{l}74 \\
79\end{array}$ & $\begin{array}{l}\text { Lim } \\
\text { Lim }\end{array}$ \\
\hline
\end{tabular}

$1 \mathrm{~N}=$ within normal limits; Lim = inferior limit; D = deficit; SS=standard score. VOSP = Visual Object and Space Perception

2 Battery; WAIS $=$ Wechsler Adult Intelligence Scale. Partial reassessment performed in 2016 revealed no improvement $(*)$ or 3 mild improvements: ${ }^{\mathrm{a}} 12 / 20,{ }^{\mathrm{b}} 5 / 10,{ }^{\mathrm{c}} 13 / 15$.

\section{$4 \quad 2.2$ Control participants}


consent; none received financial compensation for participation. Approval for the study was obtained through the local ethics committee.

\subsection{Stimuli}

Different types of unmasked PLDs were used to assess BM processing. They were derived from point-light sequences of a stationary walking human or cat (Troje, 2012; see Supplementary Video 2). Human walkers were depicted by a set of 11 markers representing the main joints and the head of a person, while cat walkers were represented by 14 dots. The PLDs were displayed upright, inverted, or scrambled (Figure 3); static stimuli were created by deriving a still from the respective video animations. Dynamic PLDs were shown facing either left or right, and walking in place, as if on a treadmill. The stimuli appeared as white dots on a black background. Gait frequencies were $.93 \mathrm{~Hz}$ for the human and $1.7 \mathrm{~Hz}$ for the cat, reflecting realistic frequencies. At a $60 \mathrm{~cm}$ viewing distance the human and cat PLDs subtended $\sim 3 \times 6^{\circ}$ (width $\times$ height) and $\sim 7 \times 3^{\circ}$ visual angle, respectively. PLDs presented in pairs were displayed side by side in the center of the screen $\left(13^{\circ}\right.$ distance between their centroids). To create scrambled PLDs, dots sampled from a normal coherent walker were relocated to a randomly selected location within the same area that was covered by the coherent PLD.

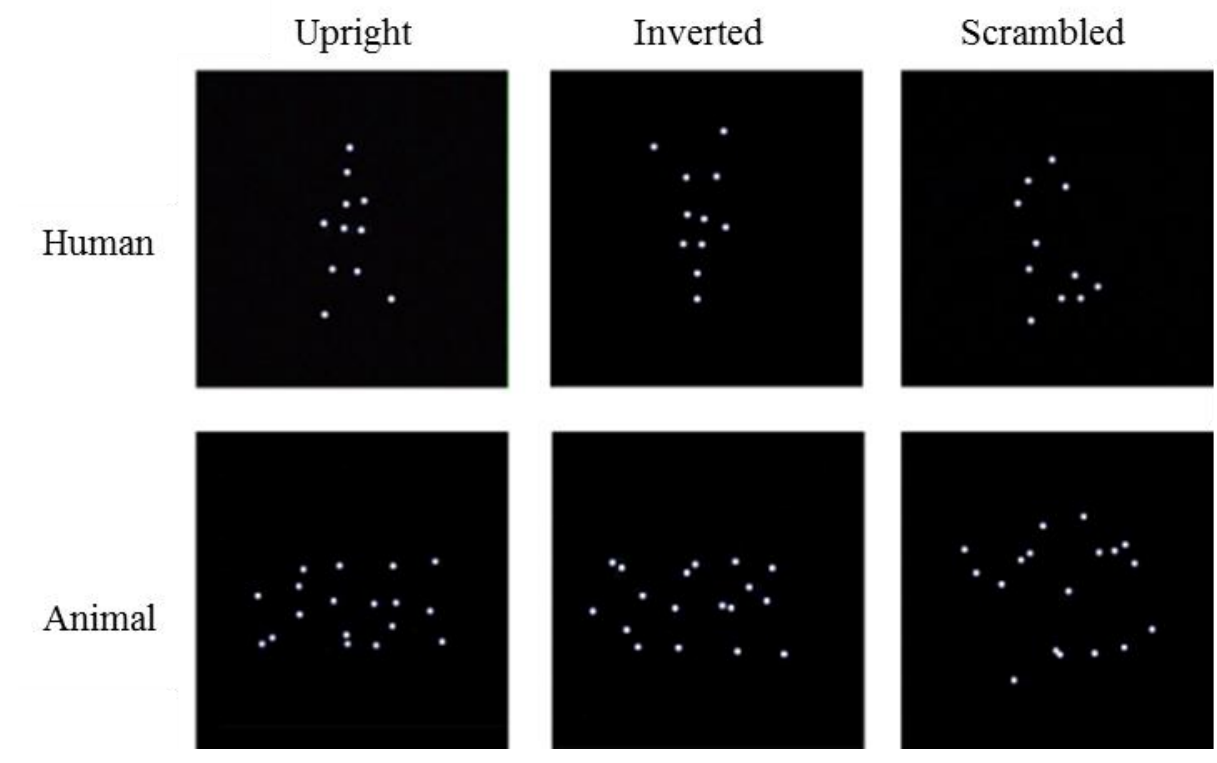

Figure 3. Individual PLD stimuli used to assess biological motion perception. For illustration of dynamic stimuli, see Supplemental Video 2. 


\subsection{Procedure}

Processing of BM was tested using two different tasks, which differed with regards to the number of stimuli displayed, and subsequently task performed. Stimuli were displayed on a portable PC computer (1280x1024 pixels spatial resolution, $85 \mathrm{~Hz}$ refresh rate), and on a VIEWPixx/3D monitor (1920x1080 pixels spatial resolution, $120 \mathrm{~Hz}$ refresh rate) during eye tracking. Each trial was initiated by the experimenter. The direction of gait depicted by a stimulus (left or right), as well as correct response location (i.e., left/right in the $2 \mathrm{AFC}$ task), were randomly selected with a constrained probability of $50 \%$ for each condition. The static or dynamic PLDs were presented for unlimited duration and could be freely explored until participants provided a verbal response that was recorded by the experimenter; no feedback was provided. Control participants completed the experiments described below in a single session; BC completed the experiments in six separate sessions, each performed on a different day.

A Pre-test was performed to assess BC's ability to detect the presence/absence of the PLDs. To this end he completed 100 trials, comprising 20 trials where nothing was presented, as well as 80 trials involving presentation of either human or animal PLDS (40 each; 20 static, 20 dynamic). On each trial, he was instructed to indicate whether a) a stimulus was present ("Is there something on the screen?"), and in the case of the presence of a stimulus, b) determine its dynamic or static nature ("Is it moving?").

Task 1 involved recognition of individually, centrally presented PLDs. Provided an incorrect or no response, three alternative choices were provided (i.e. "Is it a cat, a human, or something else?"; chance level: $33.3 \%$ ). First, 10 trials of static PLDs were completed, followed by 10 trials with dynamic PLDs.

Task 2 involved two alternative forced-choice (2AFC) decisions between simultaneously presented pairs of the stimuli used in the first task. For trials involving a human paired with a cat PLD, subjects were instructed to detect the human; for trials involving different human PLDs, they had to indicate which displayed an upright human walker. This task involved 15 blocks of 60 trials each, for 
each of the two conditions (static, dynamic). The location of the target was randomly selected and counterbalanced (50\% left; 50\% right visual field). Control participants only completed 10 trials per block, as their performance was at ceiling.

Eye movement recordings. For each task, we recorded participant's eye movements on a subset of trials. The reason this was not done for the entire number of trials was of practical nature. The patient $\mathrm{BC}$, who fatigues extremely quickly, showed normal gaze patterns on the initially acquired trials (see Results). Therefore, we discontinued eye tracking, which is technically more time consuming due to the frequent calibration required, as compared to purely behavioral testing. On these trials for which gaze data were recorded, the stimuli were presented using the Psychophysics \& Video Toolboxes (PTB-3; Brainard, 1997; Pelli, 1997) in a Matlab environment (R2010a, The MathWorks, Natick, MA, USA), on a 1920 x 1080 pixels VIEWPixx/3D monitor (refresh rate: $120 \mathrm{~Hz}$ ) at a $70 \mathrm{~cm}$ viewing distance. Eye movements were recorded via Eyelink Toolbox extensions (Cornelissen et al., 2002), using an SR Research Desktop-Mount EyeLink 2K eye-tracker, which has an average gaze position error of $\sim .25^{\circ}$, and a spatial resolution of $.01^{\circ}$. Gaze location on the screen was recorded from the dominant eye with a sampling rate of $1000 \mathrm{~Hz}$. A chin/forehead rest ensured stable head positioning. A nine-point calibration was conducted before each block; additional calibration was performed when necessary to ensure an optimal recording quality.

\subsection{Analyses}

Data analyses were performed in Python using PyMC3 (Salvatier et al., 2016) and visualized using Seaborn (Waskom et al., 2014). Eye movement raw data were preprocessed using custom scripts that employed the same filter parameters for saccade and fixation detection as the Eyelink software ( saccade velocity threshold $=30 \%$ s; saccade acceleration threshold $\left.=4000^{\circ} / \mathrm{s}\right)$. We mirrored the horizontal fixation location of trials on which the target stimulus was presented on the right side, and overlaid BC's fixation locations onto the fixation distribution of the controls (separately for young adults and age-matched controls). The spatial fixation distribution was estimated via Gaussian Kernel smoothing (full width at half maximum (FWHM) at $1^{\circ}$ visual angle), resulting in a smoothed fixation 
map for each condition per participant. Figure $4 \mathrm{a}$ and $4 \mathrm{~b}$ shows controls' eye fixation patterns during the 2AFC task, with BC's raw fixation data are superimposed in red. Moreover, to determine the fixation pattern similarity between controls and BC, we performed Pearson correlations on the fixation maps between all possible pairs of participants, independently for each condition; Figure $4 \mathrm{c}$ shows the mean derived from these similarity matrices. Figure $4 \mathrm{~d}$ indicates the average pattern similarity amongst young controls (left), as well as between the age-matched control and young controls (middle), and the patient and young controls (right).

We modeled the behavioral data from both paradigms (i.e., accuracy rate) using a betabinomial model with Bayesian parameter estimation. As an alternative to the conventional Null hypothesis significance testing (NHST), a Bayesian approach yields more consistent results under extreme cases, for instance single case studies with small number of trials (i.e., 60 trials with a binary decision) (Crawford and Garthwaite, 2007; Jaynes, 2003). Moreover, parameter estimation using Bayesian statistics returns probability distributions over the full range of possible parameter values, instead of point estimates of the most likely values (e.g., Maximum likelihood estimation). This is important as in the current experiment we aimed to estimate the patient's general recognition ability of static and dynamic stimuli. This was achieved by using a hierarchical Bayesian approach, which allowed us to estimate and compare the patient-level hyperparameters (i.e., recognition ability for static and dynamic stimuli), with the condition-level parameters simultaneously estimated in an optimal way (for the 2AFC task). Additionally, where applicable, hypotheses were tested by computing Bayes factor using the Savage-Dickey method (Wagenmakers et al., 2010).

In the beta-binomial model, the total number of accurate responses after $N$ trials follows a binomial distribution with a probability of correct response $p$, and the distribution of $p$ follows a beta distribution with parameters $\alpha$ and $\beta$ :

$$
\begin{gathered}
p \sim \operatorname{Beta}(\alpha, \beta) \\
Y \sim \operatorname{Binomial}(p, n)
\end{gathered}
$$


2 the posterior distribution of $p$ for each condition with a uniform prior $p \sim \operatorname{Beta}(\alpha=1, \beta=1)$.

3 Importantly, to infer the probability of correct response $p$ across the different conditions in the second task (2AFC between PLD pairs), we re-parameterized the beta distribution by the mode $\omega$ and the concentration $\kappa$ (Kruschke, 2015, cf. Eqn 9.4, pp. 223):

$$
\alpha=\omega(\kappa-2)+1 \text { and } \beta=(1-\omega)(\kappa-2)+1 \text { with } \kappa>2
$$

We placed a uniform distribution on the mode $\omega \sim \operatorname{Uniform}(0,1)$ as a prior, and a uniform distribution on the concentration parameter $\kappa \sim \operatorname{Uniform}(2, N)$. The parameterization using the mode instead of the mean is more intuitive for skewed distributions, since the mode is a better description of central tendency (Kruschke, 2015). Moreover, by modeling the mode $\omega$ as a hyper-parameter, we can directly infer any advantage for dynamic over static condition across a wide range of different stimuli pairs (i.e., $\left.\omega_{\text {dynamic }}-\omega_{\text {static }}\right)$.

Model parameters were estimated using PyMC3 (Salvatier et al., 2016). Monte Carlo sampling methods were used to accurately approximate the posterior distributions of the estimated parameters ( $p$ or $\omega$ ) by summarizing their estimation and uncertainty. 30,000 samples were drawn from the posterior to obtain smooth parameter estimates.

\subsection{Initial observations: Eye movement recordings}

The eye movement recordings showed that, across both tasks, BC orientated his eye gaze correctly to the stimuli presented. BC's pattern of eye movements overlaps with those of the young adult controls, as well as his age-matched control. Figure 4a and b shows the eye gaze patterns of BC and controls in one of the conditions (dynamic presentation of human upright versus animal upright) of the 2AFC discrimination task. The fixation pattern similarity is quantified using Pearson correlation coefficients reported as a similarity matrix in Figure 4c, which demonstrate that all participants displayed similar eye movement patterns. Moreover, a pair-wise permutation t-test revealed no significant differences amongst the three average correlation coefficients displayed in Figure 4d. 

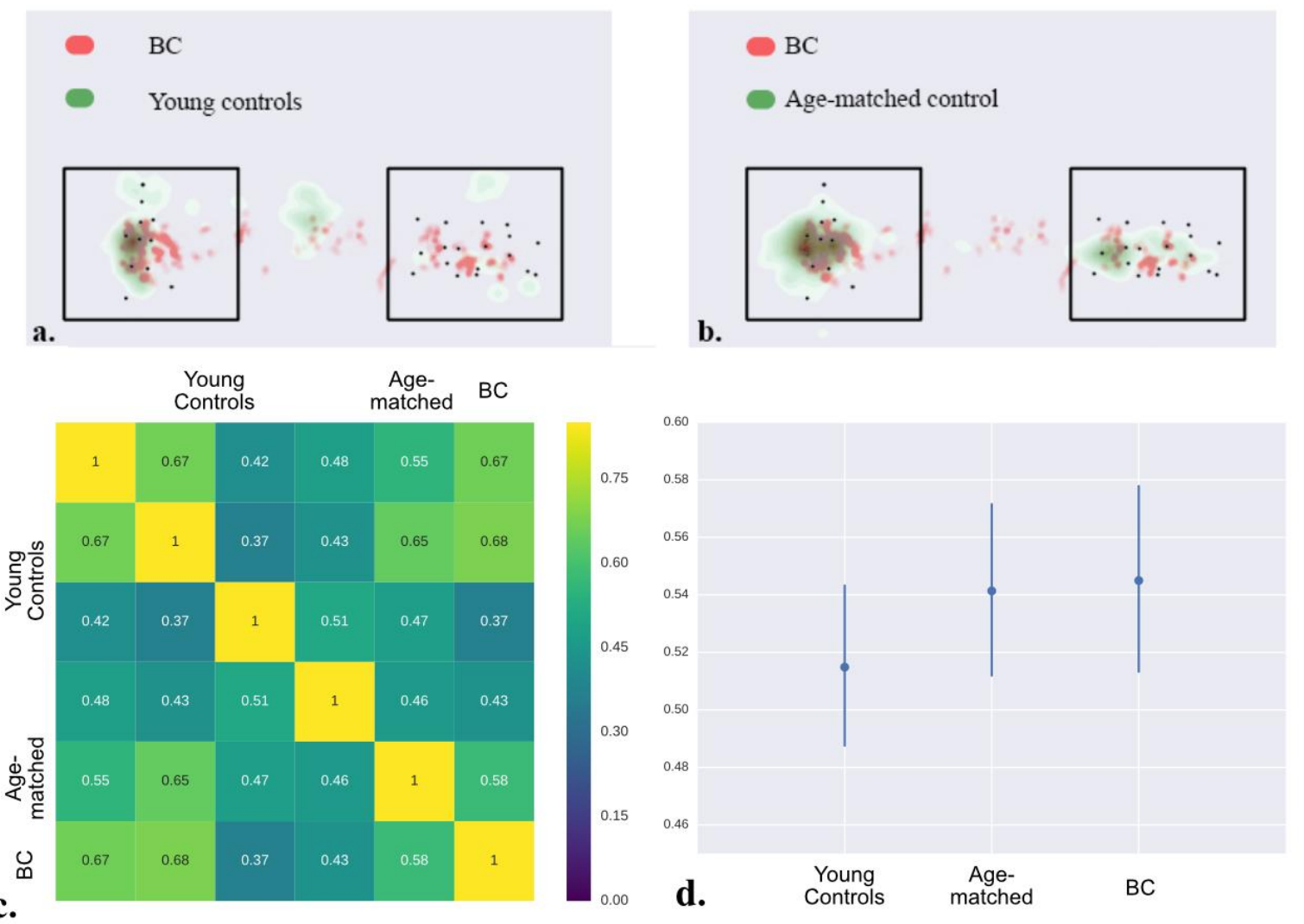

Figure 4. Participants' eye movement patterns during the $2 \mathrm{AFC}$ discrimination of dynamic, upright human and animal PLDs. On the trials displayed, subjects had to indicate the location of the human walker. BC's fixation locations (red dots) superimposed on the fixation heat map derived from a. young adult controls, and b. the age-matched control. Black squares show the locations of the presented stimuli (examples of upright human and animal walkers are superimposed in the left and right squares for illustration purposes). We recorded BC's eye movements in order to rule out the possibility of his impairment arising from an inability to fixate the diagnostic information. As his eye movements strongly resembled those of controls, we terminated acquisition of eye recordings while continuing extensive behavioral testing (see Procedure). c. Average similarity matrix derived from Pearson correlation coefficients between participants' fixation patterns per condition. d. Average pattern similarity among young controls (left), between the age-matched and young controls (center), and between BC and young controls (right); error bar display 95\% confidence intervals.

\section{Results}

\subsection{Pre-test: Stimulus detection and static vs. dynamic discrimination}

BC showed neither difficulty in determining the presence/absence of PLDs (97\%), nor in

determining whether they were static $(95 \%)$ or dynamic $(95 \%)$; all scores significantly above chance

level (one-tailed binomial tests).

\subsection{Task 1: Recognition of individually presented PLDs}

Figure 5 summarizes BC's performance for recognition of individually presented static and

dynamic PLDs. For static stimuli, contrary to healthy controls, BC was unable to identify any of the 
stimuli. Prompted to choose amongst the three alternative responses, his performance did not differ from chance ( 7 correct responses out of 20 trials; posterior estimation of accuracy $p=36.3 \%$ with the 95\% highest density interval (HDI) [17.7, 56.6]; see red line in Figure 5). For dynamic stimuli, BC was again unable to identify any of the presented PLDs, in contrast to controls who performed at ceiling. Again his performance provided the three response alternatives did not differ from chance $(6$ correct responses out of 20 trials; posterior estimation of accuracy $p=31.8 \%$ with the $95 \%$ HDI $[13.7,50.8]$; see green line in Figure 5). The Bayes factor computed using the Savage-Dickey method is 3.95 and 3.79 respectively, providing substantial evidence that performance in both conditions did not differ from chance.

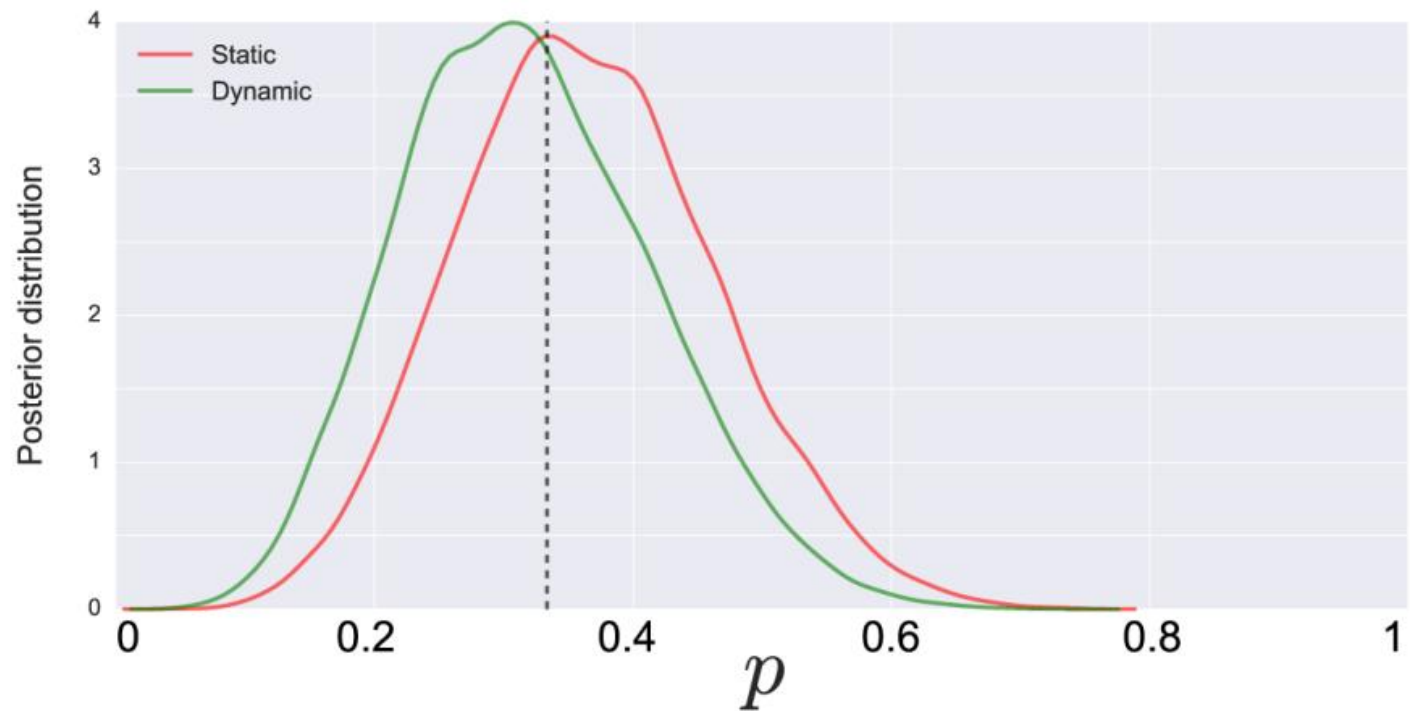

Figure 5. Posterior distribution of BC's performance for individually presented PLDs. Static and dynamic conditions are represented by red and green lines, respectively; the dashed vertical line indicates chance level. Note that the shape of the distribution represents the posterior estimation and its associated uncertainty: the more certain of the estimation, the higher the peak of the distribution.

\subsection{Task 2: Two-alternative forced choice task (2AFC) discrimination between PLD pairs}

Table 2 and Figure 6 summarize BC's performance for 2AFC decisions performed on simultaneously presented static and dynamic PLD pairs. For static PLD pairs, BC's overall performance did not differ from chance level (432 correct responses out of a total 900 trials across all conditions; posterior estimation of the mode of accuracy $p=46.8 \%$ with the $95 \%$ HDI $[31.7,62.7]$; see red line in Figure 6a). Contrariwise, for dynamic PLD pairs BC showed above chance level performance (777 correct responses out of a total 900 trials across all conditions; posterior estimation 
1 of the mode of accuracy $p=93.3 \%$ with the 95\% HDI [87.7, 99.9], see green line in Figure 6a).

2 Moreover, the posterior distribution of accuracy rates in all but one condition showed a higher

3 estimation for the dynamic compared to static condition (see Figure 6b). Indeed, by computing the

4 differences between the modes (i.e., $\omega_{\text {dynamic }}-\omega_{\text {static }}$ ) we estimated the performance improvement of the

5 dynamic condition compared to the static condition at $\Delta p=46.5 \%[29.5,63.5]$.

6 Table 2. BC's performance for the 2AFC task. For each possible stimulus pair (i.e., cell) BC's percentages of correct responses are provided for static (normal font) and dynamic (italics) conditions, respectively. Asterisks indicate conditions for which performance is significantly above chance (one-tailed binomial tests performed separately for static and dynamic conditions). Note that for trials involving a human paired with an animal PLD, subjects were instructed to detect the human; for trials involving different human (or animal) PLDs, they had to indicate which displayed an upright human (or animal) walker.

\begin{tabular}{lccccc}
\hline PLD pairs & $\begin{array}{c}\text { Human } \\
\text { upright }\end{array}$ & $\begin{array}{c}\text { Human } \\
\text { inverted }\end{array}$ & $\begin{array}{c}\text { Human } \\
\text { scrambled }\end{array}$ & $\begin{array}{c}\text { Animal } \\
\text { upright }\end{array}$ & $\begin{array}{c}\text { Animal } \\
\text { inverted }\end{array}$ \\
Human inverted & $55 \mid 87^{*}$ & & & & \\
Human scrambled & $37 \mid 88^{*}$ & $53 \mid 38$ & & & \\
Animal upright & $50 \mid 95^{*}$ & $43 \mid 93^{*}$ & $85^{*} \mid 93^{*}$ & & \\
Animal inverted & $25 \mid 88^{*}$ & $8 \mid 90^{*}$ & $83^{*}$ & $48 \mid 82^{*}$ & \\
Animal scrambled & $55 \mid 97^{*}$ & $50 \mid 95^{*}$ & $32 \mid 97^{*}$ & $58 \mid 80^{*}$ & $47 \mid 78^{*}$ \\
\hline
\end{tabular}



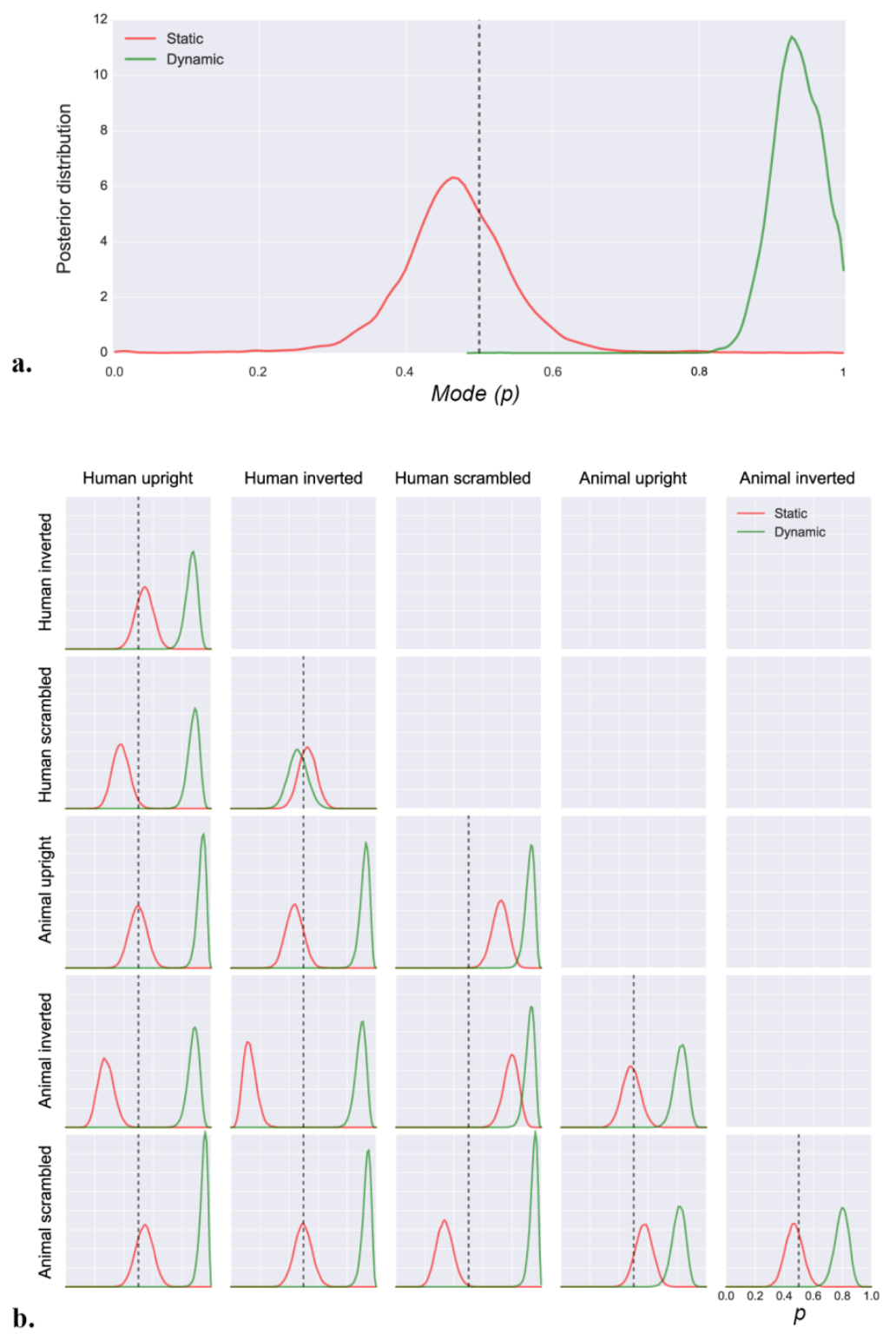

b.

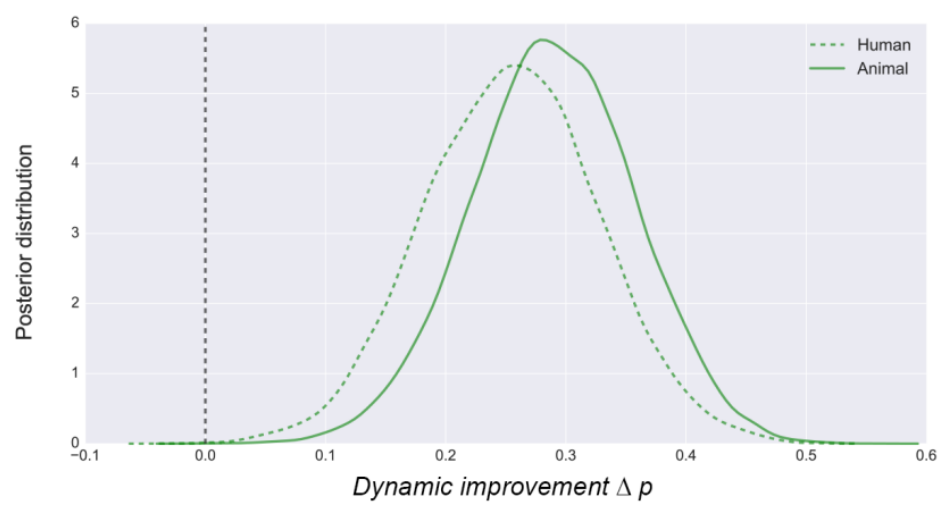

Figure 6. BC's performance for discrimination between pairs of PLDs. a. Posterior distributions of BC's overall performance. Note that the shape of the distribution represents the posterior estimation and its associated uncertainty: the more certain of the estimation, the higher the peak of the distribution. b. Results of the Bayesian hierarchical modelling performed on the data shown in Table 2. Line plots show posterior distributions of BC's recognition accuracy for each PLD pairing. c. Posterior distribution of BC's recognition improvement (dynamic - static) in the 2AFC task for trials involving pairs of human (dashed line), or animal (solid line) PLDs. Red and green lines in a. and b. represent the static and dynamic condition, respectively; dashed vertical lines represent chance level. 
To further determine whether the recognition improvement following the display of dynamic

2 stimuli is species-specific, we performed two similar Bayesian hierarchical models on data from trials

3 involving presentation of pairs of (a) human stimuli (i.e., upright vs. inverted, upright vs. scrambled, and inverted vs. scrambled), and (b) animal stimuli (same pairs as for human PLD pairs; see above). The dynamic over static recognition improvement (displayed in Figure 6c) for human stimuli is $25.4 \%$

$6 \quad[11.4,39.7]$, and $28.9 \%$ [15.5, 42.2] for animal stimuli. The Bayes factor (5.66) indicates that the performance improvement related to dynamic displays was comparable for human and animal stimuli.

\section{Discussion}

To the best of our knowledge, this is the first report of residual BM perception in a rare case of

cortical blindness due to bilateral striate damage. The patient BC is unable to visually identify objects,

but can interestingly perceive motion and even sometimes identify his wife based on her gait. We

therefore assessed BM in BC by using PLDs of static and dynamic human and animal walkers, including their inverted and scrambled versions, under different task demands. Contrary to controls, who generally performed at ceiling, $\mathrm{BC}$ was unable to identify individually presented PLDs regardless of whether they were static or conveyed motion. Strikingly, however, in the context of a $2 A F C$

discrimination task, his performance was at chance for discrimination of static images ${ }^{2}$, but significantly above chance level when dynamic PLD pairs were presented (86\%).

\section{Independence of processing form and BM}

Previous neuroimaging and patient studies have demonstrated that processing of BM involves various cerebral regions (Grosbras et al., 2012), encompassing those associated with form and motion perception (Kourtzi et al., 2008). These include the ventral premotor cortex, as well as the posterior superior temporal sulcus (pSTS; Grossman et al., 2000; Puce and Perrett, 2003; Vangeneugden et al., 2014). Disruption to either (e.g., via transcranial magnetic stimulation, or brain damage) can impair

\footnotetext{
${ }^{2}$ As demonstrated in Figure 6b, BC displayed above chance level discrimination performance in two static conditions: human scrambled vs. animal upright, and human scrambled vs. animal inverted. Conceptually speaking, we believe it is difficult to provide a solid theoretical explanation for this pattern of results. We instead would like to suggest that, the likelihood of observing by chance significant differences will increase with the number of tested combinations.
} 
perception of BM (Grossman et al., 2005; Saygin, 2007; Vaina and Gross, 2004; van Kemenade et al., 2012). Additional regions implied in processing of BM include MT+/V5 and regions of the visual form pathway, i.e. the extrastriate body area and lateral temporal cortex (Beauchamp et al., 2002; Brooks et al., 2008; Gilaie-Dotan et al., 2013; Lu, 2010; Peelen et al., 2006; Vaina et al., 2001). Until recently, it was unclear whether perception of BM critically relies on processing of object form (Beauchamp et al., 2002; Grossman and Blake, 2002; Jastorff and Orban, 2009; Lu, 2010; Vaina et al., 2001). However, Gilaie-Dotan et al. (2015) reported intact perception of BM in visual agnosic patients presenting with varied ventral lesions, thus providing compelling evidence for independent processing of BM and visual form. Our results thus add to a body of evidence suggesting that processing of BM as well as general motion are mediated by mechanisms that are distinct from those involved in processing object form.

\section{Task-dependency of residual abilities in cortical blindness}

Our findings coincide with previous studies, which reported that patients' residual abilities depend on the specific testing conditions and stimuli employed (Hervais-Adelman et al., 2015; Richoz et al., 2015; Weiskrantz et al., 1995; Zeki and Ffytche, 1998). Mirroring previous neuropsychological reports, they demonstrate that reliable discrimination can be observed under circumstances of reduced uncertainty by providing task-relevant information (Barton et al., 2002; Joubert et al., 2003; Ramon and Rossion, 2010; Ramon et al., under review). We speculate that in the 2AFC task, simultaneously increasing the available visual information and constraining the number of choice alternatives enhances residual cortical signal relative to noise. ${ }^{3}$ Thus, the present results highlight the role of topdown modulation on patients' residual visual processing abilities, which can lead to a substantial improvement in behavioral performance. This has important implications for the development of intervention and compensation strategies in visually impaired (and most probably other) patients. These should specifically incorporate knowledge concerning the conditions under which task-

\footnotetext{
${ }^{3}$ This notion is supported by other neuropsychological reports as well. For instance Battelli, Cavanagh and Thornton (2003) reported that neglect patients with parietal lesions could be, albeit slowed down, capable of determining the presence of rightward BM provided presentation of one or two PLDs, but were dramatically impaired when more than two stimuli were shown (Experiment 2a).
} 
dependent improvements and residual abilities can be observed. Whether such top-down facilitation generalizes to other aspects of vision such as color and object perception remains to be clarified in future studies.

\section{Residual processing of motion conveyed by living agents}

As described above, our 2AFC tasks involved different types of stimulus pairs. Trials could involve pairs of a) distinct categories of biological agents (animal vs. human), or b) exemplars of the same category (e.g., human upright vs. inverted). In the first case, discrimination could be based on low level information alone, i.e. the difference in the visually stimulated surface, the orientation of which differed between PLDs displaying a bi- or quadruped (i.e., vertical vs. horizontal). Importantly, $\mathrm{BC}$ also showed a BM processing advantage on trials involving within-category pairings, which did not incorporate such low-level differences. Finally, BC showed high and moreover comparable performance levels for trials involving either pairs of human or animal PLDs (see Figure 6c). Overall these observations indicate that the advantage for BM is not species-specific (Bardi et al., 2014; Simion et al., 2008; Vallortigara et al., 2005; Vallortigara and Regolin, 2006) or straightforwardly related to a strategy based on low-level stimulus properties. The processing of motion conveyed by living agents is therefore a genuine residual capacity observable in cortical blindness.

\section{Conclusions}

It has been previously suggested that residual motion processing abilities in cortical blindness are mediated by alternative pathways that bypass striate cortex (Bridge et al., 2010; Hervais-Adelman et al., 2015). Such geniculo-extrastriate pathways have been suggested to underlie MT/V5 activation in the absence of striate input (Ajina et al., 2015a, 2015b, 2015c; Barleben et al., 2015; Goebel et al., 2001; Morland et al., 2004; Schoenfeld et al., 2002; Sincich et al., 2004; Zeki, 2015). We speculate that $\mathrm{BC}$ 's residual abilities may reflect processing within other regions critically involved in BM which are probably spared, such as STS and V5.

It is worth noting that the aforementioned previous studies have focused on processing of general motion. As such the present study represents the first investigation into BM processing in a 
rare case of bilateral cortical blindness, presenting with severely impaired visual categorization (i.e., color, shapes, faces and objects). Since additional MRI was not possible in BC, our future efforts are directed towards developing non-invasive neuroimaging techniques (e.g. NIRS, EEG) for further investigation of this unique patient. This will serve to specify the extent of his (extra)striate damage and determine whether and if which regions are spared. Moreover, we aim to investigate the neurofunctional correlates of $\mathrm{BM}$ in greater detail in this rare case to disentangle the respective roles of e.g. STS in BM processing, and address how task demands shape neural responses in structurally intact cortices given absent or restricted striate input.

\section{Acknowledgments}

We thank BC and his wife for their continued cooperation, Vincent Junod for assistance during data acquisition, as well as Neil Docherty and two anonymous reviewers for helpful comments on a previous version of the manuscript. This research was not supported by any specific grant from funding agencies in the public, commercial, or not-for-profit sectors.

\section{Conflict of Interest Statement}

The authors declare that the research was conducted in the absence of any commercial or financial relationships that could be construed as a potential conflict of interest.

\section{References}

Ajina, S., Kennard, C., Rees, G., Bridge, H., 2015a. Motion area V5/MT+ response to global motion in the absence of V1 resembles early visual cortex. Brain 138, 164-78 doi: 10.1093/brain/awu328. doi:10.1093/brain/awu328

Ajina, S., Pestilli, F., Rokem, A., Kennard, C., Bridge, H., 2015b. Human blindsight is mediated by an intact geniculo-extrastriate pathway. Elife 4, 1-23. doi:10.7554/eLife.08935

Ajina, S., Rees, G., Kennard, C., Bridge, H., 2015c. Abnormal Contrast Responses in the Extrastriate Cortex of Blindsight Patients. J. Neurosci. 35, 8201-8213. doi:10.1523/JNEUROSCI.307514.2015

Aldrich, M.S., Alessi, A.G., Beck, R.W., Gilman, S., 1987. Cortical blindness: etiology, diagnosis, and 
prognosis. Ann. Neurol. 21, 149-158. doi:10.1002/ana.410210207

Barbur, J.L., Watson, J.D., Frackowiak, R.S., Zeki, S., 1993. Conscious visual perception without V1. Brain 116, 1293-1302. doi:10.1093/brain/116.6.1293

Bardi, L., Regolin, L., Simion, F., 2014. The first time ever I saw your feet: Inversion effect in newborns' sensitivity to biological motion. Dev. Psychol. 50, 986-93. doi:10.1037/a0034678

Barleben, M., Stoppel, C.M., Kaufmann, J., Merkel, C., Wecke, T., Goertler, M., Heinze, H.J., Hopf, J.M., Schoenfeld, M.A., 2015. Neural correlates of visual motion processing without awareness in patients with striate cortex and pulvinar lesions. Hum. Brain Mapp. 36, 1585-1594. doi:10.1002/hbm.22725

Barton, J.J.S., Press, D.Z., Keenan, J.P., O’Connor, M., 2002. Lesions of the fusiform face area impair perception of facial configuration in prosopagnosia. Neurology 58, 71-78. doi:10.1212/WNL.58.1.71

Battelli, L., Cavanagh, P., Thornton, I.M., 2003. Perception of biological motion in parietal patients. Neuropsychologia 41, 1808-1816. doi:10.1016/S0028-3932(03)00182-9

Beauchamp, M.S., Lee, K.E., Haxby, J. V., Martin, A., 2002. Parallel visual motion processing streams for manipulable objects and human movements. Neuron 34, 149-159. doi:10.1016/S0896-6273(02)00642-6

Bender, M.D., Furlow, F.T., 1945. Visual disturbances produced by lateral lesions of the occipital lobe with central scotomas. Arch. Neurol. Psychiatry 53, 165-170.

Bottari, D., Troje, N.F., Ley, P., Hense, M., Kekunnaya, R., Röder, B., 2015. The neural development of the biological motion processing system does not rely on early visual input. Cortex 71, 359367. doi:10.1016/j.cortex.2015.07.029

Bova, S.M., Giovenzana, A., Signorini, S., La Piana, R., Uggetti, C., Bianchi, P.E., Fazzi, E., 2008. Recovery of visual functions after early acquired occipital damage. Dev. Med. Child Neurol. 50, 311-315. doi:10.1111/j.1469-8749.2008.02044.x

Brainard, D.H., 1997. The Psychophysics Toolbox. Spat. Vis. 10, 433-436. doi:10.1163/156856897X00357

Bridge, H., Hicks, S.L., Xie, J., Okell, T.W., Mannan, S., Alexander, I., Cowey, A., Kennard, C., 2010. Visual activation of extra-striate cortex in the absence of V1 activation. Neuropsychologia 48, 4148-4154. doi:10.1016/j.neuropsychologia.2010.10.022 
Brooks, A., Schouten, B., Troje, N.F., Verfaillie, K., Blanke, O., van der Zwan, R., 2008. Correlated changes in perceptions of the gender and orientation of ambiguous biological motion figures. Curr. Biol. 18, 728-729. doi:10.1016/j.cub.2008.06.054

Burra, N., Hervais-Adelman, A., Kerzel, D., Tamietto, M., de Gelder, B., Pegna, A.J., 2013. Amygdala Activation for Eye Contact Despite Complete Cortical Blindness. J. Neurosci. 33, 10483-10489. doi:10.1523/JNEUROSCI.3994-12.2013

Caine, D., Watson, J.D.G., 2000. Neuropsychological and neuropathological sequelae of cerebral anoxia: A critical review. J. Int. Neuropsychol. Soc. 6, 86-99. doi:10.1017/S1355617700611116

Carey, D.P., Goodale, M.A., Sprowl, E.G., 1990. Blindsight in rodents: The use of a "high-level" distance cue in gerbils with lesions of primary visual cortex. Behav. Brain Res. 38, 283-289. doi:10.1016/0166-4328(90)90182-E

Chen-Plotkin, A.S., Pau, K.T., Schmahmann, J.D., 2008. Delayed leukoencephalopathy after hypoxicischemic injury. Arch. Neurol. 65, 144-145. doi:10.1001/archneurol.2007.7

Cornelissen, F.W., Peters, E.M., Palmer, J., 2002. The Eyelink Toolbox: Eye tracking with MATLAB and the Psychophysics Toolbox. Behav. Res. Methods, Instruments, Comput. 34, 613-617. doi:10.3758/BF03195489

Crawford, J.R., Garthwaite, P.H., 2007. Comparison of a single case to a control or normative sample in neuropsychology: development of a Bayesian approach. Cogn. Neuropsychol. 24, 343-372. doi:10.1080/02643290701290146

de Gelder, B., Tamietto, M., van Boxtel, G., Goebel, R., Sahraie, A., van den Stock, J., Stienen, B.M.C., Weiskrantz, L., Pegna, A., 2008. Intact navigation skills after bilateral loss of striate cortex. Curr. Biol. 18, 1128-1129. doi:10.1016/j.cub.2008.11.002

de Gelder, B., Vroomen, J., Pourtois, G., Weiskrantz, L., 1999. Non-conscious recognition of affect in the absence of striate cortex. Neuroreport 10, 3759-3763. doi:10.1097/00001756-19991216000007

Denny-Brown, D., Chambers, R.W., 1955. Visuomotor functions in the cerebral cortex. J. Nerv. Ment. Dis. $121,288-289$.

Flanagan, C., Kline, L., Curè, J., 2009. Cerebral blindness. Int. Ophthalmol. Clin. 49, 15-25. doi:10.1097/IIO.0b013e3181a8e040

Giaschi, D., Jan, J.E., Bjornson, B., Young, S.A., Tata, M., Lyons, C.J., Good, W. V, Wong, P.K., 2003. Conscious visual abilities in a patient with early bilateral occipital damage. Dev. Med. 
Gilaie-Dotan, S., Kanai, R., Bahrami, B., Rees, G., Saygin, A.P., 2013. Neuroanatomical correlates of biological motion detection. Neuropsychologia 51, 457-463. doi:10.1016/j.neuropsychologia.2012.11.027

Gilaie-Dotan, S., Saygin, A.P., Lorenzi, L.J., Rees, G., Behrmann, M., 2015. Ventral aspect of the visual form pathway is not critical for the perception of biological motion. Proc. Natl. Acad. Sci. 112, E361-E370. doi:10.1073/pnas.1414974112

Goebel, R., Muckli, L., Zanella, F.E., Singer, W., Stoerig, P., 2001. Sustained extrastriate cortical activation without visual awareness revealed by fMRI studies of hemianopic patients. Vision Res. 41, 1459-1474. doi:10.1016/S0042-6989(01)00069-4

Grosbras, M.H., Beaton, S., Eickhoff, S.B., 2012. Brain regions involved in human movement perception: A quantitative voxel-based meta-analysis. Hum. Brain Mapp. 33, 431-454. doi:10.1002/hbm.21222

Grossman, E.D., Battelli, L., Pascual-Leone, A., 2005. Repetitive TMS over posterior STS disrupts perception of biological motion. Vision Res. 45, 2847-2853. doi:10.1016/j.visres.2005.05.027

Grossman, E.D., Blake, R., 2002. Brain areas active during visual perception of biological motion. Neuron 35, 1167-1175. doi:10.1016/S0896-6273(02)00897-8

Grossman, E.D., Donnelly, M., Price, R., Pickens, D., Morgan, V., Neighbor, G., Blake, R., 2000. Brain areas involved in perception of biological motion. J. Cogn. Neurosci. 12, 711-20. doi:10.1162/089892900562417

Hadad, B., Schwartz, S., Maurer, D., Lewis, T.L., 2015. Motion perception: a review of developmental changes and the role of early visual experience. Front Integr.Neurosci. 9, 49.

Hadad, B.S., Maurer, D., Lewis, T.L., 2012. Sparing of sensitivity to biological motion but not of global motion after early visual deprivation. Dev. Sci. 15, 474-481. doi:10.1111/j.14677687.2012.01145.x

Hervais-Adelman, A., Legrand, L.B., Zhan, M., Tamietto, M., de Gelder, B., Pegna, A.J., 2015. Looming sensitive cortical regions without V1 input: evidence from a patient with bilateral cortical blindness. Front. Integr. Neurosci. 9, 1-12. doi:10.3389/fnint.2015.00051

Jastorff, J., Orban, G.A., 2009. Human functional magnetic resonance imaging reveals separation and integration of shape and motion cues in biological motion processing. J. Neurosci. 29, 7315-29. doi:10.1523/JNEUROSCI.4870-08.2009 
Jaynes, E.T., 2003. Probability Theory: The logic of Science, Cambridge University press. doi:10.1017/CBO9781107415324.004

Johansson, G., 1973. Visual perception of biological motion and a model for its analysis. Percept. Psychophys. 14, 201-211. doi:10.3758/BF03212378

Joubert, S., Felician, O., Barbeau, E., Sontheimer, A., Barton, J.J., Ceccaldi, M., Poncet, M., 2003. Impaired configurational processing in a case of progressive prosopagnosia associated with predominant right temporal lobe atrophy. Brain 126, 2537-2550. doi:10.1093/brain/awg259

Kourtzi, Z., Krekelberg, B., van Wezel, R.J.A., 2008. Linking form and motion in the primate brain. Trends Cogn. Sci. doi:10.1016/j.tics.2008.02.013

Kruschke, J., 2015. Doing Bayesian data analysis: A tutorial introduction with R JAGS, and Stan, Igarss 2014.

Lu, H., 2010. Structural processing in biological motion perception. J. Vis. 10, 13. doi:10.1167/10.12.13

Margolin, E., Gujar, S.K., Trobe, J.D., 2007. Isolated cortical visual loss with subtle brain MRI abnormalities in a case of hypoxic-ischemic encephalopathy. J. Neuroophthalmol. 27, 292-296. doi:10.1097/WNO.0b013e31815c42b4

Morland, A.B., Lê, S., Carroll, E., Hoffmann, M.B., Pambakian, A., 2004. The role of spared calcarine cortex and lateral occipital cortex in the responses of human hemianopes to visual motion. J. Cogn. Neurosci. 16, 204-218. doi:10.1162/089892904322984517

Neri, P., Morrone, M.C., Burr, D.C., 1998. Seeing biological motion. Nature 395, 894-6. doi:10.1038/27661

Peelen, M. V., Wiggett, A.J., Downing, P.E., 2006. Patterns of fMRI activity dissociate overlapping functional brain areas that respond to biological motion. Neuron 49, 815-822. doi:10.1016/j.neuron.2006.02.004

Pegna, A.J., Khateb, A., Lazeyras, F., Seghier, M.L., 2005. Discriminating emotional faces without primary visual cortices involves the right amygdala. Nat. Neurosci. 8, 24-25. doi:10.1038/nn1364

Pelli, D.G., 1997. The VideoToolbox software for visual psychophysics: transforming numbers into movies. Spat. Vis. 10, 437-442. doi:10.1163/156856897X00366

Puce, A., Perrett, D., 2003. Electrophysiology and brain imaging of biological motion. Philos. Trans. 
Ramon, M., Busigny, T., Gosselin, F., Rossion, B., n.d. All new kids on the block? Impaired holistic processing of personally familiar faces in a kindergarten teacher with acquired prosopagnosia. doi:10.13140/RG.2.1.3183.4486

Ramon, M., Rossion, B., 2010. Impaired processing of relative distances between features and of the eye region in acquired prosopagnosia-Two sides of the same holistic coin? Cortex 46, 374-389. doi:10.1016/j.cortex.2009.06.001

Richoz, A.R., Jack, R.E., Garrod, O.G.B., Schyns, P.G., Caldara, R., 2015. Reconstructing dynamic mental models of facial expressions in prosopagnosia reveals distinct representations for identity and expression. Cortex 65, 50-64. doi:10.1016/j.cortex.2014.11.015

Riddoch, G., 1917. Dissociation of visual perceptions due to occipital injuries, with especial reference to appreciation of movement. Brain 40, 15-57. doi:10.1093/brain/40.1.15

Salvatier, J., Wiecki, T. V., Fonnesbeck, C., 2016. Probabilistic programming in Python using PyMC3. PeerJ Comput. Sci. 2, e55. doi:10.7717/peerj-cs.55

Sanders, M.D., Warrington, E., Marshall, J., Wieskrantz, L., 1974. "Blindsight”: Vision in a Field Defect. Lancet 303, 707-708. doi:10.1016/S0140-6736(74)92907-9

\section{Sawada, H., Udaka, F., Seriu, N., Shindou, K., Kameyama, M., Tsujimura, M., 1990. MRI} demonstration of cortical laminar necrosis and delayed white matter injury in anoxic encephalopathy. Neuroradiology 32, 319-321. doi:10.1007/BF00593053

Saygin, A.P., 2007. Superior temporal and premotor brain areas necessary for biological motion perception. Brain 130, 2452-2461. doi:10.1093/brain/awm162

Schoenfeld, M.A., Heinze, H.-J., Woldorff, M.G., 2002. Unmasking Motion-Processing Activity in Human Brain Area V5/MT+ Mediated by Pathways That Bypass Primary Visual Cortex. Neuroimage 17,769-779. doi:10.1006/nimg.2002.1204

Shefrin, S.L., Goodin, D.S., Aminoff, M.J., 1988. Visual evoked potentials in the investigation of "blindsight". Neurology 38, 104-9.

Simion, F., Regolin, L., Bulf, H., 2008. A predisposition for biological motion in the newborn baby. Proc. Natl. Acad. Sci. 105, 809-813. doi:10.1073/pnas.0707021105

Sincich, L.C., Park, K.F., Wohlgemuth, M.J., Horton, J.C., 2004. Bypassing V1: a direct geniculate input to area MT. Nat. Neurosci. 7, 1123-1128. doi:10.1038/nn1318 
Troje, N., 2012. What is biological motion?: Definition, stimuli and paradigms. Soc. Percept. Detect. Interpret. animacy, agency, Intent. 1-19.

Tsutsui, J., Ichihashi, K., Kimura, H., 1984. Dynamic topography of visual evoked potentials and extrageniculate projection in case of Riddoch phenomenon. Jpn.J.Ophthalmol. 28, 20-30.

Vaina, L.M., Cowey, A., Eskew Jr., R.T., LeMay, M., Kemper, T., 2001. Regional cerebral correlates of global motion perception: evidence from unilateral cerebral brain damage. Brain 124, 310 321. doi:10.1093/brain/124.2.310

Vaina, L.M., Gross, C.G., 2004. Perceptual deficits in patients with impaired recognition of biological motion after temporal lobe lesions. Proc. Natl. Acad. Sci. U. S. A. 101, 16947-51. doi:10.1073/pnas.0407668101

Vallortigara, G., Regolin, L., 2006. Gravity bias in the interpretation of biological motion by inexperienced chicks. Curr. Biol. doi:10.1016/j.cub.2006.03.052

Vallortigara, G., Regolin, L., Marconato, F., 2005. Visually inexperienced chicks exhibit spontaneous preference for biological motion patterns. PLoS Biol. 3, 1312-1316. doi:10.1371/journal.pbio.0030208

van Kemenade, B.M., Muggleton, N., Walsh, V., Saygin, A.P., 2012. Effects of TMS over Premotor and Superior Temporal Cortices on Biological Motion Perception. J. Cogn. Neurosci. 24, 896904. doi:10.1162/jocn_a_00194

Vangeneugden, J., Peelen, M. V, Tadin, D., Battelli, L., 2014. Distinct neural mechanisms for body form and body motion discriminations. J. Neurosci. 34, 574-85. doi:10.1523/JNEUROSCI.403213.2014

Wagenmakers, E.J., Lodewyckx, T., Kuriyal, H., Grasman, R., 2010. Bayesian hypothesis testing for psychologists: A tutorial on the Savage-Dickey method. Cogn. Psychol. 60, 158-189. doi:10.1016/j.cogpsych.2009.12.001

Waskom, M., Meyer, K., Hobson, P., Halchenko, Y., Koskinen, M., Miles, A., Wehner, D., Botvinnik, O., Megies, T., cynddl, Ziegler, E., Yarkoni, T., Zaytsev, Y. V., Coelho, L.P., Cole, J.B., Augspurger, T., diego0020, Hoppe, T., Seabold, S., Cloud, P., Hoyer, S., Qalieh, A., Allan, D., 2014. seaborn: v0.5.0 (November 2014). doi:10.5281/zenodo.12710

Weiskrantz, L., 2009. Blindsight: a case study spanning 35 years and new developments. Oxford University Press, Oxford.

Weiskrantz, L., Barbur, J.L., Sahraie, A., 1995. Parameters affecting conscious versus unconscious 
1

2

3 Weiskrantz, L., Warrington, E.K., Sanders, M.D., Marshall, J., 1974. Visual capacity in the

6

9

10

11

visual discrimination with damage to the visual cortex (V1). Proc. Natl. Acad. Sci. 92, 61226126. doi:10.1073/pnas.92.13.6122 hemianopic field following a restricted occipital ablation. Brain A J. Neurol. 97, 709-728. doi:10.1093/brain/97.1.709

Zeki, S., 2015. A massively asynchronous, parallel brain. Philos. Trans. R. Soc. B Biol. Sci. 370, 20140174-20140174. doi:10.1098/rstb.2014.0174

Zeki, S., Ffytche, D.H., 1998. The Riddoch syndrome: Insights into the neurobiology of conscious vision. Brain 121, 25-45. doi:10.1093/brain/121.1.25

Zihl, J., 2000. Rehabilitation of visual disorders after brain injury. Psychology, Hove. 